\title{
Fe y Teología: riesgo y humildad Meditar desde el corazón de María ${ }^{1}$
}

\author{
Carlos María Galli
}

Facultad de Teología - Pontificia Universidad Católica Argentina galli@uca.edu.ar

Recibido 12.3.2020/ Aprobado 15.05.2020

DOI: $h$ ttps://doi.org/10.46553/teo.57.132.2020.p9-40

María guardaba todas estas cosas meditándolas en su corazón (Lc 2,19).

La luz de la fe no disipa todas nuestras tinieblas, sino que, como una lámpara, guía nuestros pasos en la noche, y esto basta para caminar (LF 57).

+ Fernando Miguel Gil - In memoriam

+ Juan Carlos Scannone - In memoriam

ResUMEN

Este texto, es el discurso inaugural del Decano en el inicio del año, y lo editamos en el bloque de investigaciones dado el carácter intensamente teológico académico de su contenido. Es una profunda meditación que, partiendo de la experiencia histórica analiza la fe como riesgo, encuentro con Jesús, experiencia teologal y desafío sinodal y comunitario. Por ello es el misterio de María donde esta experiencia se aprende y se nutre. La tradición cristiana enseña a leer, contemplar y meditar en la escuela de María. En ella se dan los dos aspectos de la fe que generan la teología: creer y entender, asentir y pensar, confiar y meditar, aceptar y comprender. Así avanzó

- El autor es Decano de la Facultad de Teología de la Pontificia Universidad Católica Argentina y miembro de la Comisión Teológica Internacional.

1 Discurso del Sr. Decano, Pbro. Dr. Carlos María Galli, en el Acto de Inicio del Año Académico en la Facultad de Teología de la UCA el 12/03/2020, cuando se declaraba la pandemia y antes de que la Argentina entrara en cuarentena. 
en la peregrinación de la fe y desde su corazón nos enseña a hacer teología. María es el símbolo de la teología como sabiduría del corazón y corazón de la sabiduría.

Palabras clave: Fe; Escucha; Credere Deum; Amare Deum; María; Humildad

\section{Faith and Theology: Risk and Humility Meditate from the Heart of Mary}

\section{Abstract}

This text is the Dean's inaugural speech at the beginning of the year, and we edited it in the research block given the intensely academic theological nature of its content. It is a profound meditation that, based on historical experience, analyzes faith as a risk, an encounter with Jesus, a theological experience and a synodal and community challenge. Therefore, it is the mystery of Mary where this experience is learned and nurtured. Christian tradition teaches how to read, contemplate and meditate at the school of Mary. In it there are two aspects of faith that generate theology: believe and understand, agree and think, trust and meditate, accept and understand. Thus, he advanced in the pilgrimage of faith and from his heart he teaches us to do theology. Mary is the symbol of theology as wisdom of the heart and heart of wisdom.

Keywords: Faith; Listens; Credere Deum; Amare Deum; Maria; Humility

\section{Queridos amigos y amigas}

En 2020 se cumplen 105 años de nuestra Facultad de Teología y 60 del comienzo de la integración en la Universidad Católica Argentina. En este año la Congregación para la Educación Católica aprobó por quinta vez nuestros Estatutos después del Concilio Vaticano II. Por primera vez la Facultad ingresó en la franja 51-100 del ranking elaborado por la consultora Quacquarelli Symonds (QS).

Hace poco falleció nuestro querido amigo Fernando Gil. En 1978 ingresó como alumno de la Facultad y en 2018 dejó de ser profesor de Historia de la Iglesia al ser nombrado obispo de Salto en Uruguay. De estos 40 años recuerdo cuatro hechos. En 1980 dirigí un seminario para estudiar la antropología del Papa Juan Pablo II. Fernando me propuso traducir del inglés una ponencia del cardenal Karol Wojtyla que encontró en las Actas del Congreso Internacional 
por los 700 años de la muerte de santo Tomás de Aquino. Se titulaba The acting person. Fernando era un contemplativo actuando, un actuante. En 1984 me pidió si yo podía dar con él el curso sobre Dios en el seminario de Morón. En 2002 le pregunté si podía ser vicedecano cuando yo asumiera como decano. Prefirió ser director de la Biblioteca, un cargo que ejerció durante 15 años. Entre tantas cosas, le debemos la informatización de la Facultad y la nueva Biblioteca. En 2010 fue todo junto: director de la biblioteca y la revista, y vicedecano a cargo del decanato. Al final de este acto lo evocaremos junto a sus familiares y amigos.

En 2016 Fernando publicó su último texto como teólogo historiador: 'El tiempo es el mensajero de Dios'. Esbozos para una teología de la historia del Papa Francisco. ${ }^{2}$ Allí analiza el pensamiento de tres discípulos de san Ignacio de Loyola: el fundador san Pedro Fabro, el misionero Antonio Garriga, el padre Jorge Mario Bergoglio - Francisco. En su exhortación Evangelii gaudium el Papa afirma: el tiempo es mensajero de Dios (EG 171); el tiempo es superior al espacio (EG 222). Pedro Fabro decía que «Dios es el único que nos puede dar el tiempo»y se interrogaba «acerca de la cuenta que hemos de dar del tiempo». Para Fernando esos dichos remiten al tiempo como un don que Dios nos da para discernir su voluntad y a la historia como un proceso que se recorre, conmemora y proyecta en el Pueblo de Dios. Fernando comenta esta frase: cada día es un breve diseño de toda la vida. En nombre de la Facultad doy gracias por el diseño que Dios le dio a su vida y él siguió cada día, hasta el último. Su testimonio enseña a vivir cada jornada según el diseño de Dios y peregrinar en el tiempo animados por la esperanza del futuro - futurum - y del permanente adviento - adventus - de Dios.

Al iniciar este Año Académico - un nuevo tiempo que Dios nos da para compartir y aprender juntos - quiero pensar con ustedes sobre el tema Fe y teología: riesgo y humildad. Meditar desde el

2 Cf. Fernando Gil, «El tiempo es el mensajero de Dios. Esbozos para una teología de la historia del Papa Francisco», en En el Camino de Emaus: Esperanza que fecunda la historia, ed. Sociedad Argentina de Teología (Buenos Aires: Agape libros, 2017), 61-100. 
corazón de María, porque ella, la Madre de Jesús, fue «feliz por haber creído» (Lc 1,45), vivía el tiempo desde la fe y "guardaba todas estas cosas meditándolas en su corazón" (Lc 2,19.51). En la primera parte analizaré el riesgo de creer y la humildad de hacer teología o pensar en y desde la fe (I); en la segunda sección intentaré mirar a María y aprender a meditar teologalmente desde su corazón (II).

\section{Del riesgo de la fe a la humildad de la teología}

\section{El riesgo de la experiencia de la fe}

Los seres humanos vivimos entre la seguridad del hogar y la incertidumbre del camino. Buscamos equilibrar la tranquilidad del apego a las raíces y el riesgo del vuelo de las alas. La condición propia de homo viator nos hace andar, navegar, volar en la insecuritas. En ese itinerario vital estamos sometidos a la dialéctica interminable entre un desamparo en el amparo y un amparo en el desamparo. En 2020 estamos golpeados por situaciones de desasosiego que hacen vulnerable la vida. Un $40 \%$ de los argentinos sufre la pobreza de ingresos que no les deja vivir dignamente. Todos estamos afectados por el desastre ecológico denunciado por el Sínodo amazónico y la exhortación Querida Amazonia de Francisco, y por la pandemia del coronavirus que genera temor y angustia, produce millones de contagios y causa miles de muertes. En la crisis cuesta encontrar «un amparo en el desamparo» (eine Geborgenheit in die Ungeborgenheit). ${ }^{3}$ A todos nos cuesta asumir el riesgo de vivir con confianza.

Toda fe es una actitud de confianza en otro. Al creer lo que otro nos manifiesta arriesgamos la capacidad de confiar mediante un vínculo personal. Más allá de las verdades que podemos conocer por el testimonio ajeno, lo que se pone en juego es la entrega a la fiabilidad de otra persona. En esta fidelidad que sabe darse, el ser 
humano encuentra certeza y seguridad. Al mismo tiempo, aventurarse a confiar en el testimonio de otro no disipa los temores y las dudas. Pero la inseguridad de uno mismo encuentra un punto de equilibrio en el abandono confiado a la alteridad de otro, de otra, de otros. La identidad y la alteridad se construyen mutuamente en los vínculos de la relacionalidad confiada. Los padres trasmiten gradualmente a sus hijos la confianza necesaria para afrontar la vida sin estar solos. Desde niños aprendemos con la pedagogía del riesgo y la educación en la confianza.

La capacidad y la decisión de confiarse uno mismo y de confiar la propia vida a otra persona constituyen actos humanos muy significativos. También nuestro pensamiento, que busca sabiduría y verdad, necesita ser sostenido por el diálogo confiado con otros. Por eso la amistad y el banquete siempre han dado un clima cordial y propicio para pensar en común. Vivimos buscando el sentido pleno de la vida y nos alegramos al encontrar personas de las cuales podemos fiarnos. En muchos ámbitos confiamos en personas expertas que conocen las cosas mejor que nosotros. Tenemos confianza en el maestro que nos enseña, en el arquitecto que nos construye la casa, el médico que nos opera.

Tenemos necesidad de alguien que sea fiable y experto en las cosas de Dios. Dios se revela como verdadero, fiable y fiel, Aquel a quien podemos creer y en quien nos podemos apoyar porque es el Dios del Amén (Is 65,16). Dios es la Roca firme para edificar nuestra casa existencial. Jesús es la Piedra angular para construir el edificio de la vida. Él, el Hijo único, el Dios Unigénito, narra y explica al Padre invisible (cf. Jn 1,18). Cristo no es sólo aquel en quien creemos, la mayor manifestación del amor de Dios, sino también aquel con quien nos unimos para creer. La fe no sólo mira a Jesús, sino que mira desde el punto de vista de Jesús, nos hace participar en su modo de ver. Creer es mirar con tus ojos Señor y darle a la vida todo su valor. Canten todos: la alegría de vivir en Dios

Cuesta arriesgarse a vivir de la fe en Dios. Pero Dios se arriesgó primero en el amor. «Dios amó tanto al mundo, que entregó a su Hijo 
único para que todo el que cree en él no muera, sino que tenga Vida eterna» (Jn 3,16). Movido por su amor, Dios se arriesgó al rechazo de nuestra libertad. Jesús se expuso por amor y sufrió la oposición hasta la muerte en la cruz. Pero Dios sigue golpeando amorosamente la puerta de cada corazón y se sigue arriesgando a que le abramos desde dentro. El soneto de Lope de Vega exclama: «iQué tengo yo que mi amistad procuras / qué interés se te sigue Jesús mío / que a mi puerta, cubierto de rocío / pasas las noches del invierno a oscuras?» Si Dios nos amó y se confió primero, si se arriesgó y se sigue arriesgando, ¿Cómo no responderle con el riesgo de la fe? ${ }^{4}$

La luz de la fe, recibida de Cristo, Luz de Luz y Luz del mundo, no libera del acoso de las tinieblas, ni elimina los peligros nocturnos. En la encíclica Lumen fidei Francisco dice que la fe, "como una lámpara, guía nuestros pasos en la noche, y esto basta para caminar" (LF 57). A veces es como la luz de un gran faro que cubre el cielo, la tierra y el mar; habitualmente es como una pequeña antorcha que alumbra cada paso. Cuanto más oscura está la noche, más se nota la pequeña llama. La fe "ve" en la medida en que se camina por el sendero marcado por Dios, con la certeza de que la última hora de la noche será la primera de la mañana. Esa experiencia espiritual atraviesa la vida y marca los estudios teológicos. A los alumnos les digo: ¡Déjense iluminar por la fe, la guía a los caminantes!

La dialéctica de la fe en el Dios, que asumió la noche de la cruz y brilló en la mañana de la pascua, asume la tensión entre la oscuridad y la luz. Dionisio - gran teólogo del siglo VI que expuso el conocimiento dialéctico y analógico de Dios - lo expresó con imágenes contrapuestas: divino Rayo de tinieblas, misteriosas Tinieblas del no-saber, luminosa oscuridad, rayo luminoso, divina tiniebla / luz inaccesible, luz que hace invisible la tiniebla. Su teología mística, más allá de afirmar y negar algo acerca de Dios, expresa de forma paradojal la eminencia de su misterio que nos excede. 
«Trinidad supraesencial, más que divina y más que buena! Maestra de la sabiduría divina de los cristianos, guíanos más allá del no-saber y de la luz, hasta la cima más alta de las Escrituras místicas. Allí los misterios de la Palabra de Dios son simples, absolutos, inmutables en las tinieblas más que luminosas del silencio que muestra los secretos. En medio de las más negras tinieblas, ellos desbordan fulgurantes de luz». ${ }^{5}$

El riesgo de la fe, que penetra en la teología, se refleja también en la metáfora de la barca que navega en un mar de aguas embravecidas. La Constitución conciliar Gaudium et spes sigue enseñando que la Iglesia vive en el mundo actual. La Iglesia es la barca de Pedro conducida por el único Salvador que entregó su vida para salvar al mundo, no el arca de Noé para salvarse del mundo. Como Pedro, confiando en la Palabra del Señor (Lc 5,5), navegamos hacia aguas más profundas. ¿Cómo podía en aquel tiempo un barquito recorrer largas distancias y atravesar mares embravecidos por las tormentas de los vientos y las olas? Un adagio latino dice velis remisque. También hoy debemos confiar que Jesús guía la barca de la fe y podemos unir el modesto esfuerzo de nuestros brazos, que mueven los remos, con la enorme fuerza del Soplo del Espíritu, que empuja las velas. Con las velas y los remos. Esta confianza se redimensiona por la tempestad que azota al mundo con la pandemia. El Papa Francisco, solo en la Plaza San Pedro, clama: Todos estamos en la misma barca; nadie se salva solo.

\section{La fe como encuentro con Jesús, el Cristo}

La fe surge de la escucha de la Palabra de Dios. San Pablo utiliza la fórmula fides ex auditu, «la fe nace de la predicación que se escucha» (Rm 10,17). El conocimiento asociado a la palabra es personal: reconoce la voz y responde libremente. A veces se contrapone esta escucha bíblica a la visión, que parecería ser más propia de la cultura griega. La luz posibilita la contemplación de la totalidad, 
pero parece quitar espacio a la libertad porque llega directamente a los ojos, sin esperar respuesta. Sin embargo, el Antiguo Testamento combina la escucha de la Palabra de Dios con el deseo de ver su Rostro. El oído posibilita la llamada personal y obediente; la vista aporta la visión del plan divino.

La conexión entre creer, ver y escuchar es clave en el Evangelio de san Juan. La escucha de la fe distingue la voz del Buen Pastor (cf. Jn 10,3-5); llama al seguimiento, como los primeros discípulos, que «oyeron sus palabras y siguieron a Jesús» (Jn 1,37). Por otra parte, creer y ver están entrelazados: «El que cree en mí [...] cree en el que me ha enviado. Y el que me ve a mí, ve al que me ha enviado» (Jn 12,44-45). Gracias a la unión con la escucha, la fe se presenta como un camino de la mirada. En la mañana de Pascua María Magdalena ve a Jesús y anuncia la buena noticia «He visto al Señor» (Jn 20,18). La Carta a los Hebreos invita a que fijemos la mirada en Jesús ( $\mathrm{Hb} 12,2)$. Si el don de la fe que se recibe es escucha y mirada, el testimonio de la fe que se comunica se hace palabra e imagen.

Jesús, a quien se puede ver y oír, unifica la escucha y la mirada. Él es la Palabra hecha carne, cuya gloria contemplamos (Jn 1,14). Su Rostro revela al Padre invisible: «El que me ha visto, ha visto al Padre» (Jn 14,9). «Escuchamos a Jesús, la Palabra de Dios en persona; miramos a Jesús, la Imagen de Dios en persona». 6 La luz del amor se enciende cuando somos tocados en el corazón. Por eso la fe también es un tocar. «Lo que hemos oído, lo que hemos visto con nuestros propios ojos [...] y palparon nuestras manos acerca de la Palabra de Vida es lo que les anunciamos» (1 Jn 1,1). Por la Encarnación del Verbo, Dios quiere que experimentemos su amor y le amemos de un modo connatural con nuestra condición humana. Jesús nos ha tocado y por los sacramentos nos sigue tocando. Con la fe podemos tocarlo y recibir su gracia sanadora, como la hemorroísa lo tocó para curarse (Lc 8,45-46). Creer es tocar a Cristo con el corazón. «Con el corazón se cree», dice san Pablo (Rom 10,10).

6 Cf. Olegario González de Cardedal, El rostro de Cristo (Madrid: Encuentro, 2012), 19. 
La lógica de la mirada, la escucha y el contacto inspira no sólo la relación personal con Dios, sino también la comunicación con el Pueblo de Dios. Este es un rasgo del estilo pastoral latinoamericano del Papa Francisco que sabe que todos necesitamos ser mirados, escuchados y abrazados con amor: «Es necesario que haya un contacto. Es necesario tocar a la gente, acariciarla. El tacto es el sentido más religioso de los cinco. Hace bien dar la mano a los niños, a los enfermos, apretar las manos, acariciar... Mirar a los ojos en silencio. Esto también es contacto».? Manteniendo la primacía de Dios y de las sorpresas de su gracia en la vida pastoral, es necesario descubrir y tocar al Dios que vive en la ciudad, en las mediaciones humanas que prologan la humanidad de Cristo. Entre ellas podemos destacar las figuras simbólicas de las imágenes sagradas, los misterios profundos de la vida humana, el testimonio amoroso de los santos «de la puerta de al lado». ${ }^{8}$

El don del encuentro es la raíz permanente de la comunión discipular con el Señor. El cuarto Evangelio cuenta el impacto que produjo Jesús en Juan y Andrés. Todo comenzó con una pregunta: «¿Qué buscan?» (Jn 1,38). Le siguió la invitación a compartir un momento: «vengan y lo verán» (Jn 1,39). El encuentro con Jesús es un don porque, a diferencia de lo que sucedía en el discipulado de esa época, él toma la iniciativa, elige y llama a sus discípulos para que lo sigan, no para que aprendan una doctrina o una interpretación de la Ley. El discipulado es un estilo de vida permanente por la comunión con la Persona, el mensaje, la actuación, el destino y la misión de Jesús. La elección gratuita y el vínculo de fe caracterizan su seguimiento. ${ }^{9}$ Los discípulos miran y escuchan al Maestro con fe.

7 Antonio Spadaro, «Le orme di un pastore. Una conversazione con Papa Francisco» en Jorge Mario Bergoglio - Papa Francesco, Nei tuoi occhiè la mia parola. Omelie e discorsi di Buenos Aires 1999-2013 (Milano: Rizzoli, 2016), XVII.

$8 \mathrm{Cf}$. Carlos M. Galli, Dios vive en la ciudad. Hacia una nueva pastoral urbana a la luz de Aparecida y del proyecto misionero de Francisco (Buenos Aires: Agape - Herder, $20144^{a}$. edición corregida y aumentada), 207-212.

9 Cf. Luis H. Rivas, «Discípulos para la misión en el Nuevo Testamento», Teología 94 (2007): 473-505. 
La alegría de la fe mueve a comunicar el don del encuentro con Cristo de una forma desbordante y agradecida. El encuentro con Jesús es un don - no una conquista - que revela la gratuidad de Dios. Una cristología del don conduce a una cristología del encuentro, en la medida en que encuentro es una palabra que designa no sólo el primer paso sino todo el camino de comunión con Jesús en la fe. Es un término personalista que expresa un aspecto del ser / estar / vivir en Cristo, lo que puede ser llamado discipulado, configuración, amistad, permanencia. Encuentro es una noción empleada por la teología de la revelación y la fe, por la cristología en sus distintas vertientes; ${ }^{10}$ por la teología espiritual y pastoral. Alcanza a todo encuentro con el Señor que se da en la vida, también en esta Facultad.

Una clave hermenéutica de este pontificado está en la alegría de anunciar el Evangelio. ${ }^{11}$ Recogiendo el testamento pastoral de san Pablo VI, Francisco llama a cultivar la dulce y confortadora alegría de evangelizar (EN 80; EG 14-18). «La alegría evangelizadora siempre brilla sobre el trasfondo de la memoria agradecida: es una gracia que necesitamos pedir» (EG 13). Ante la acedia individualista y el pesimismo estéril alienta «la alegría evangelizadora» (EG 83). «La alegría del Evangelio que llena la vida de la comunidad de los discípulos es una alegría misionera» (EG 21).

La fe se fortalece dándola con alegría porque comunica el Amor de Dios manifestado en Cristo. «Nosotros hemos conocido el amor que Dios nos tiene y hemos creído en él» (1 Jn 4,16). La fe tiene una forma misionera porque mueve al creyente a salir al encuentro de todos los hombres. La palabra de Cristo, una vez escuchada y creída, por su propio dinamismo, se transforma en respuesta y en palabra pronunciada, en confesión de fe. Como dice san Pablo: «Con el corazón se cree [...] y con los labios se profesa» $(\operatorname{Rm} 10,10)$.

10 La primera de las cristologías de Olegario González de Cardedal, Jesús de Nazaret. Aproximación a la cristología (Madrid: BAC, 1975), emplea encuentro, la cual es una clave permanente de su cristología sistemática, como camino es la noción decisiva de su cristología fundamental. Cf. Fundamentos de Cristología I. El Camino (Madrid: BAC, 2005), XXXI.

11 Cf. Francisco, «Libres y obedientes», L'Osservatore romano (edición semanal en lengua española), 28/10/2016, 7 . 
La fe personal no es una actividad privada, sino que nace de la escucha atenta, se vuelve confesión testimonial y debe convertirse en anuncio para los otros. "Cómo creerán en aquel de quien no han oído hablar? ¿Cómo oirán hablar de él sin nadie que anuncie?» (Rm 10,14).

\section{La lógica teologal: del credere in Deum al amare Deum}

Jesucristo es el Camino a la Verdad y la Vida. El Hijo de Dios, al venir a habitar entre nosotros (Jn 1,14) abre el camino a la comunión con Dios (Jn 1,18). Ante la pregunta de Tomás: «"Señor, no sabemos a dónde vas. ¿Cómo vamos a conocer el camino?" Jesús responde: “Yo soy el Camino, la Verdad y la Vida. Nadie va al Padre, sino por mí"» (Jn 14,5-6). Él se identifica con el sujeto "Yo Soy» -que evoca el nombre de Dios - y tres predicados: «el Camino, la Verdad y la Vida».

La relación personal con Jesús por la fe se expresa en los varios usos que hace san Juan del verbo «creer» ( $\pi 1 \sigma \tau \varepsilon v \varepsilon \imath v$, credere), que aparece 98 veces en su evangelio. Junto a la forma "creer que"

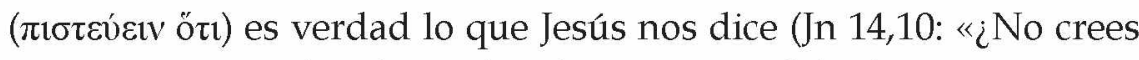
que yo estoy en el Padre y el Padre está en mí?»), el cuarto evangelio usa las fórmulas «creer a» Jesús y «creer en» Jesús. «Creemos a»

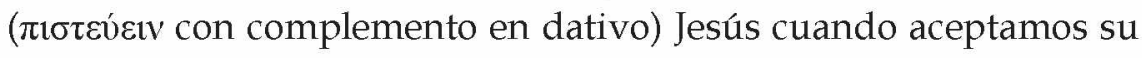
Palabra y su testimonio, porque es veraz (cf. Jn 6,30: «¿Qué signos haces para que veamos y te creamos?»). «Creemos en» Jesús cuando lo acogemos personalmente, nos confiamos a él y lo seguimos por el camino de la vida (cf. Jn 12,44: «El que cree en / hacia mí, en realidad no cree en mí, sino en Aquel que me envío»). Este aspecto es tan novedoso del cristianismo que el cuarto evangelio forjó una formulación original, usando el verbo con complemento en acusativo y la preposición ciç: «crean en Dios y crean también en mí» (Jn 14,1). El Símbolo de la fe se expresa con esta fórmula que indica la entrega personal. El texto latino dice: credo, credimus... in Deum... in Iesum Christum... in Spiritum Sanctum. 
Desde entonces la teología católica considera varios aspectos del acto de la fe: la adhesión al Dios que nos revela la belleza de su gloria como testigo y garante (credere Deo); el conocimiento del Dios unitrino revelado en Jesucristo como misterio supremo y verdad primera (credere Deum); la orientación o tendencia de la vida del creyente hacia el Dios - Amor como bondad primera y fin último. La comprensión del contenido de la fe (fides quae) se sitúa en el seno de una actitud creyente que supone el variado acto de creer (fides qua). La fe es asentimiento a Dios, pensamiento de Dios, abandono en Dios. Esa triple formalidad puede ayudar al hablar tanto de perplejidad como de certeza de la fe.

Deseo destacar el aspecto por el cual el acto del creyente se dirige hacia Cristo como la meta hacia la que se encaminan los pasos. El don de la fe lleva a creer hacia Dios (credere in Deum) como el Fin y la Felicidad de la vida. Francisco asevera que en la fe vivida por el pueblo cristiano hay que acentuar más "el credere in Deum que el credere Deum" (EG 124). Esto significa, para la teología agustiniana y tomista (ST II-II, 2, 2), que el credere in Deum, la orientación hacia Dios como el Sentido supremo de la vida, sostenido en el credere Deo o adhesión confiada a Dios, tiene prioridad sobre el credere Deum o conocimiento creyente de lo revelado acerca de Dios y de su plan salvador para el hombre y el mundo. El conocimiento de la fe se ubica en un movimiento que va del asentimiento confiado a la entrega amorosa. Por eso, la experiencia teologal y la atención pastoral han de concentrarse más en la fe que se hace entrega en la piedad filial y el amor fraterno, y no sólo en el desarrollo conceptual de sus contenidos (EG 124), sin dejarlo de lado por la circularidad que hay entre inteligencia y voluntad en la fe. Esta interpretación es común a teólogos y pastoralistas argentinos de varias generaciones. ${ }^{12}$

12 Cf. Ricardo Ferrara, «Fidei infusio y revelación en Santo Tomás de Aquino: Summa Theologiae I-II q. 100 a. 4 ad 1 m», Teología 23-24 (1974): 24-32; Rafael Tello, La nueva evangelización (Buenos Aires: Agape, 2008), 47-52; Enrique Bianchi, Pobres en este mundo, ricos en la fe. La fe de los pobres de América Latina según Rafael Tello (Buenos Aires: Agape, 2012), 167-232. 
El creer hacia Dios (in Deum) se consuma en el amar a Dios (amare Deum), en el amor de caridad que une a Dios y al prójimo en Dios, porque «Dios es Amor» (1 Jn 4,8). Solo cree quien ama y solo ama quien cree. La fe mueve un paso esperanzado para seguir el camino más perfecto del amor (1 Cor 12,31). «En Cristo Jesús... cuenta... la fe que actúa por medio del amor» (Gal 5,6). La Sabiduría de Dios nos comunica la sabiduría del amor. "El amor de Dios ha sido derramado en nuestros corazones por el Espíritu Santo, que nos ha sido dado" $(\mathrm{Rm} 5,5)$. La gracia genera la experiencia de estar enamorado de Dios, que mueve a conocerlo con todo el corazón. ${ }^{13}$ El método es solo una guía hacia el don, un sendero de purificación afectiva, intelectual y espiritual para pensar con una fe amorosa.

El Dios cognoscible y conocido como amor, amable y amante, guía al creyente que sólo ama lo que conoce y que, por una íntima dialéctica complementaria, conoce mejora quien ama. «El que ama... conoce a Dios» (1 Jn 4,7-8). Conocer el amor de Dios en Cristo, que supera todo nuestro conocer, muestra que el amor no es el absoluto más allá del ser, sino su profundidad y su altura, su anchura y su longitud. Hay que comprenderlo como amor y como don, lo que también interesa a la filosofía fenomenológica de la religión, ${ }^{14}$ si se anima a pensar el Principio en su capacidad de donar y donarse. ${ }^{15}$

La fe como inclinación hacia Dios - credere in Deum - es atribuida a la unción del Espíritu Santo y, por eso, a él se lo vincula al conocimiento por connaturalidad. De ella nace la sabiduría, que lleva a juzgar de todo según el sentir divino. Es un conocimiento por contacto o connaturalidad con lo conocido, un conocer teologal, afectivo y sabroso porque el gozo es efecto de la unión de amor. Francisco insiste en la relación entre las formas históricas de la piedad popular y la obra del Espíritu: «en la piedad popular, por ser

13 Cf. Bernard Lonergan, Método en Teología (Salamanca: Sígueme, 1972), 236.

14 Cf. Jean Greisch, Le buisson ardent et les lumieres de la raison II (Paris: Cerf, 2002), 291-334

15 Cf. Paul Gilbert, Le ragioni della sapienza (Roma: Gregorian \& Biblical Press, 2010), 134; Jean-Luc Marion, «La fede e la ragione» en Credere per vedere, (Torino: Lindau, 2012), 37-54. 
fruto del Evangelio inculturado, subyace una fuerza activamente evangelizadora que no podemos menospreciar: sería desconocer la obra del Espíritu Santo» (EG 126).

\section{Nosotros creemos: la forma eclesial y sinodal de la fe}

El acto de fe se dice en la primera persona del singular - yo creo - y en la primera persona del plural - nosotros creemos. Decir yo creo es decir que yo adhiero a lo que nosotros creemos. La Iglesia es el sujeto comunitario de la fe. Ninguno cree solo; creemos por y con otros. El acto personal del creyente reposa sobre la fe de la comunidad. Ella no es una relación exclusiva entre el "yo" del sujeto creyente y el "Tú" del Dios creído. La fe se vive en el "nosotros", como nos recuerda la forma dialogada del Credo de origen bautismal. La Iglesia es el Sujeto que pronuncia el Símbolo de la Fe.

La eclesialidad de la fe es un don que, a veces, puede ser percibido como un obstáculo, sobre todo cuando la Iglesia sufre crisis de credibilidad. ${ }^{16}$ Hoy las llagas del cuerpo eclesial escandalizan a algunos y provocan una fe vacilante en otros. La dimensión eclesial se torna más pesada cuando la comunidad carga con traumas institucionales. Entonces la crisis de la fe en Dios que hay en la cultura se intensifica con otra crisis referida a la credibilidad de la Iglesia. Hoy el riesgo de creer incluye la alegría y la cruz de sentir con la Iglesia. Ella está llamada a la conversión permanente. Ella es como la luna. Debe dejarse transfigurar para reflejar la Luz del Sol que nace de los alto: Cristo. ${ }^{17}$

La doctrina católica afirma que no creemos en la Iglesia del mismo modo con el que creemos en Dios. La Iglesia es sujeto de la fe, comunidad de fe, esperanza y amor. Profesa el Credo diciendo: Credimus... Amen. A su modo, ella también es objeto de la fe porque

16 Cf. Christoph Theobald, La lezione di teologia (Bologna: EDB, 2014), 11-16.

$17 \mathrm{Cf}$. Hans Waldenfels, La svolta. Lo stile della Chiesa al tempo di papa Francesco (Bologna: EDB, 2018), $51-69$. 
se integra en el Credo trinitario asociada a la fe en el Espíritu Santo. Decimos: Credimus ... Ecclesiam. El Símbolo profesa la fe en las tres Personas divinas empleando la formula credere in Deum. En cambio, la Iglesia es creída como una obra de Dios. Creemos la Iglesia - credimus ecclesiam - en modo acusativo sin preposición, no creemos en o hacia ella - in ecclesiam - porque el acto del creyente culmina en el Espíritu que santifica la Iglesia (cf. ST II-II, 1, 9, ad 5um). El Catecismo de la Iglesia Católica afirma:

\begin{abstract}
«Creer que la Iglesia es Santa y Católica, y que es Una y Apostólica (como añade el Símbolo Nicenoconstantinopolitano), es inseparable de la fe en Dios, Padre, Hijo y Espíritu Santo. En el Símbolo de los Apóstoles, hacemos profesión de creer que existe una Iglesia Santa (Credo... Ecclesiam), y no de creer en la Iglesia para no confundir a Dios con sus obras y para atribuir claramente a la bondad de Dios todos los dones que ha puesto en su Iglesia (cf Catech. Rom. 1, 10, 22)» (CCE 750).
\end{abstract}

El Concilio Vaticano II enseña que la Iglesia es misterio / sacramento de comunión del Pueblo de Dios peregrino y misionero en la historia. Con el Papa argentino la teología del Pueblo de Dios recupera ese lugar central, desdibujado desde 1985 en algunos documentos magisteriales. Esta eclesiología está vinculada, en forma mediata, a un pensamiento gestado en la comunidad teológica argentina, sobre todo en nuestra Facultad de Teología, ${ }^{18}$ y, de modo inmediato, a una reflexión sobre la religiosidad popular hecha por un grupo de jesuitas argentinos - al que pertenecía Bergoglio - en el ámbito del Colegio Máximo de San Miguel, centrada en el pueblo fiel como sujeto de un modo de vivir la fe y de crear cultura en una trama histórica concreta. ${ }^{19}$ El nombre "teología del pueblo" es sugestivo, pero, dicho en abstracto resulta simplificador si "pueblo" sólo evoca una comunidad secular de carácter cultural o político. La reflexión argentina comprende dos sentidos análogos del concep-

18 Cf. Juan Carlos Scannone, La teología del pueblo (Santander: Sal Terrae, 2017), 15-93; $181-274$

19 Cf. José Luis Narvaja, «Miguel Ángel Fiorito. Una riflessione sulla religiosità popolare nell'ambiente di Jorge Mario Bergoglio», La Civiltà Cattolica 4027 (2018): 18-29; Massimo Borghesi, Jorge Mario Bergoglio. Una biografia intellettuale. Dialettica e mistica (Milano: Jaca Book, 2017), 67-77. 
to pueblo, uno eclesial y otro civil. Me gusta decir que algunos de nosotros pensamos una teología del Pueblo de Dios, de los pueblos y las culturas, $y$ de la pastoral popular, porque incluimos una eclesiología, una teología de la cultura y la historia, y una teología pastoral que considera la misión de la Iglesia en los pueblos y une la piedad popular con la opción por los pobres en teoría y práctica. ${ }^{20}$

En 2015 Francisco presentó la sinodalidad como dimensión constitutiva de la Iglesia. El Pueblo de Dios sigue a Jesús, «el Camino» (Jn 14,6), reúne a «los seguidores del Camino del Señor» (Hch 9,2; 18,25). Este caminar juntos alcanza momentos culminantes cuando los discípulos de Jesús se reúnen juntos para discernir la marcha evangelizadora bajo el impulso del Espíritu y la guía de los pastores, e interpretar los signos de los tiempos a la luz del Evangelio. El 7 de marzo pasado se anunció que el Papa asignó el tema de la sinodalidad a la próxima asamblea ordinaria del Sínodo de los Obispos en 2022. El título es: Por una Iglesia sinodal: comunión, participación y misión.

El Pueblo de Dios es el sujeto de la comunión sinodal. Francisco propuso una Iglesia sinodal con la imagen de una pirámide invertida. «Jesús ha constituido la Iglesia poniendo en su cumbre al Colegio apostólico, en el que el apóstol Pedro es la "roca" (cf. Mt 16,18), aquel que debe "confirmar" a los hermanos en la fe (cf. Lc 22,32 ). Pero en esta Iglesia, como en una pirámide invertida, la cima se encuentra por debajo de la base». ${ }^{21}$ La reinversión de la figura fue iniciada por el Vaticano II. ${ }^{22}$

En el orden paradojal de la sinodalidad la base del Pueblo de Dios es situada en la cúspide de la figura y el vértice petrino se coloca abajo, dando un nuevo punto de apoyo. Este orden invertido mira

20 Cf. C. M. Galli, «El "retorno" del "Pueblo de Dios"» en Virginia R. Azcuy; José C. Caamaño; Carlos M. Galli, La Eclesiología del Concilio Vaticano I/ (Buenos Aires: Agape - Facultad de Teología UCA, 2015), 405-471.

21 Francisco, «Discurso en la Conmemoración del 50 Aniversario de la institución del Sínodo de los Obispos» (17/1 0/2015), L'Osservatore romano 23/10/2015, 9.

22 Ghislain Lafont, Petit essai sur le temps du pape Francois (Paris: Cerf, 2017), 26; cf. 131 $197,218-233,251-260$. 
el ministerio apostólico - colegial y primacial - como un servicio a la comunión eclesial. Francisco vincula el primado del Amor de Dios y la primacía del Pueblo de Dios: «el orden sinodal es una manera de expresar el primado del Amor - Misericordia (de Dios) en el nivel de la Iglesia». ${ }^{23}$

En 2018 la Comisión Teológica Internacional emitió su documento La sinodalidad en la vida y en la misión de la Iglesia, que piensa no sólo la sinodalidad en la Iglesia sino la sinodalidad de la Iglesia. ${ }^{24} \mathrm{La}$ palabra "sínodo" designa, ante todo, un estilo que califica el modo ordinario de vivir la comunión sacramental del Pueblo de Dios en camino. Incluye las estructuras y los procesos que expresan la comunión a nivel institucional en la Iglesia local, regional y universal. E integra la celebración de acontecimientos en los cuales se actúa sinodalmente, las asambleas sinodales, desde los concilios ecuménicos a los sínodos diocesanos. Hoy se habla de estilo, estructura, proceso y asamblea sinodal (cf. SIN 70). En este año se celebra la Asamblea del I Sínodo de la arquidiócesis de Buenos Aires. Desde 2017, en el inicio del trienio que está por concluir, la Facultad recorre diversos procesos sinodales para discernir en común lo que Dios desea de nuestra misión teológica institucional.

La sinodalidad expresa la condición de sujeto de toda la Iglesia y de todos en la Iglesia. Los Bautizados y las Bautizadas somos compañeros de camino del Señor y estamos llamados a ser sujetos activos en el itinerario de la fe hacia la santidad misionera. Por eso Francisco, completando una expresión del Vaticano II (LG 12a), habla de la Iglesia como el santo Pueblo fiel de Dios. La Unción del Espíritu Santo hace a los fieles sujetos de iniciativa en la "pirámide invertida" de la Iglesia. La doctrina del sensus fidei expresa ese carácter de sujeto activo propio de todos los fieles cristianos. 268.

23 Ghislain Lafont, Petit essai sur le temps du pape Francois ... 138; cf. 190. 194, 202, 252,

24 Comisión Teológica Internacional, La sinodalidad en la vida y en la misión de la lglesia (Buenos Aires: Agape, 2018). Se abrevia SIN seguido del número del párrafo correspondiente. 
El documento El 'sensus fidei' en la vida de la Iglesia de la Comisión Teológica Internacional distingue el sensus fidei fidelis, el instinto personal que tiene cada creyente en comunión con la Iglesia, y el sensus fidei fidelium, la forma eclesial del sentido de la fe. Su expresión más notable es el consensus fidei o sensus Ecclesiae que atestigua que una doctrina pertenece a la fe apostólica. El sensus fidei es una fuente de discernimiento y una vertiente de la sinodalidad. Se expresa, diversamente, en la práctica de la consulta a los fieles y en la piedad católica popular. ${ }^{25}$ Los laicos, mujeres y varones, participan de la función profética de Cristo y tienen un "instinto" $\mathrm{u}$ "olfato" para percibir lo que Dios desea en las nuevas circunstancias vitales. Por eso deben ser consultados y pueden aportar al discernimiento eclesial desde sus carismas, sobre todo en cuestiones de su competencia secular.

\section{La humildad de la teología y del teólogo}

Caminamos sinodalmente en la fe. Quienes estudiamos teología estamos sostenidos por el testimonio de la fe vivida con amor y expresada con esperanza por los miembros del pueblo cristiano. Debemos nutrirnos de la sabiduría de tantos pobres en este mundo, pero enriquecidos por Dios en la fe (cf. Sgo 2,5). "Las expresiones de la piedad popular tienen mucho que enseñarnos $y$, para quien sabe leerlas, son un lugar teológico al que debemos prestar atención" (EG 126). La sabiduría del Pueblo de Dios nos enseña a vivir la fe a todos, también a los que los que recibimos el ministerio ordenado y a los que nos formamos teológicamente. Benedicto XVI destacó el tesoro escondido de la religión popular latinoamericana, manifestó su vital pertenencia a la Iglesia y dijo que ella «hace que nosotros mismos (los eclesiásticos) nos integremos plenamente en el Pueblo de Dios». ${ }^{26}$

25 Cf. Comisión Teológica Internacional, El «sensus fidei» en la vida de la lglesia (Madrid: BAC, 2014), 107-126.

26 Benedicto XVI, «Piedad popular y nueva evangelización» en Pontificia Comisión para América Latina, La piedad popular en el proceso de evangelización de América Latina (Vaticano: LEV, $2011), 15$. 
Los que hacemos teología debemos aprender - y también enseñar - la fe del Pueblo de Dios.

«Para los teólogos, el sensus fidelium es de gran importancia. No es solo un objeto de atención y respeto, es también una base y un locus para su trabajo. Por un lado, los teólogos dependen del sensus fidelium, porque la fe que exploran y explican vive en el Pueblo de Dios. Está claro, por tanto, que los mismos teólogos deben participar en la vida de la Iglesia para tener verdaderamente conocimiento de ella. Por otro lado, es precisamente parte del servicio específico de los teólogos, dentro del Cuerpo de Cristo, explicar la fe de la Iglesia tal como se encuentra en las Escrituras, la liturgia, credos, dogmas, catequesis, y en el sensus fidelium mismo. Los teólogos ayudan a aclarar y articular el contenido del sensus fidelium, reconociendo y mostrando que los aspectos relativos a la verdadera fe pueden ser complejos, y que su investigación debe ser precisa. Les toca también a ellos, en ocasiones, examinar críticamente expresiones de la piedad popular, nuevas corrientes de pensamiento y nuevos movimientos en el seno de la Iglesia en nombre de la fidelidad a la Tradición apostólica. Las afirmaciones críticas de los teólogos deben ser siempre constructivas; deben ofrecerse con humildad, respeto y caridad: "El conocimiento (gnosis) engríe, mientras que el amor (agape) edifica" (1 Cor 8,1)».27

El Papa Benedicto XVI dedicó muchas catequesis a figuras espirituales y teológicas de la Iglesia patrística y medieval. En el contexto de la teología escolástica, se refirió al pensamiento del franciscano Juan Duns Scoto. En su tiempo, la mayoría de los teólogos oponía una objeción a la doctrina según la cual María estuvo exenta del pecado original desde el primer instante de su concepción. Pensaban que la universalidad de la redención de Cristo podía quedar comprometida por esa afirmación semejante, como si María no hubiera necesitado del Salvador. Para que se comprendiera esta preservación del pecado original, Duns Scoto desarrolló un valioso argumento, que en 1854 el Papa Pío IX adoptó al definir solemnemente el dogma de la Inmaculada Concepción. Es el argumento de la «redención preventiva» según el cual la Inmaculada representa la obra maestra de la redención realizada por Cristo, quien preservó a su Madre del pecado original. Por tanto, María es totalmente

27 Comisión Teológica Internacional, La Teología hoy (Buenos Aires: Agape, 2012), 35; un análisis más detallado de la cuestión en el documento posterior El «sensus fideì en la vida de la Iglesia ...81-84, 106-112. 
redimida por Cristo. Scoto enriqueció con su pensamiento lo que el Pueblo de Dios ya creía espontáneamente y manifestaba en la piedad y en el arte. La fe en la Inmaculada estaba en el Pueblo de Dios mientras que la teología buscaba la clave para interpretarla en la totalidad de la doctrina.

«Por tanto, el Pueblo de Dios precede a los teólogos y todo esto gracias a ese sobrenatural sensus fidei, es decir, a la capacidad infusa del Espíritu Santo, que habilita para abrazar la realidad de la fe con la humildad del corazón y de la mente. En este sentido, el Pueblo de Dios es «magisterio que precede», y que después la teología debe profundizar y acoger intelectualmente. ¡Ojalá los teólogos escuchen siempre esta fuente de la fe y conserven la humildad y la sencillez de los pequeños! ${ }^{28}$

Estamos llamados a aprender de los demás y apoyarnos mutuamente en la fe. A los nuevos alumnos los invito a transitar con humildad el camino de esta escuela de teología. También los profesores debemos aprender a enseñar y enseñar a aprender, aprender a aprender y enseñar a enseñar. San Pablo nos recomienda: «Ayúdense mutuamente a llevar las cargas» (Gal 6,2). El verbo griego usado en esa frase es hypomenein, que significa sostener, soportar. Debemos sobrellevar juntos, con amor, el regalo y la carga de profesar y pensar la fe, porque «el amor todo lo soporta» (1 Cor 13,7).

Los que nos arriesgamos a creer estamos acompañados por una caravana de peregrinos y una nube de testigos. Nos sostienen los santos, comenzando por quienes viven en la puerta de al lado y se sientan en el banco de al lado. Nos ayuda la intercesión de los mártires, los testigos más auténticos de la fe. Ellos hallaron el sentido de su vida en el corazón de Cristo y saben que nada ni nadie - ni la violencia ni el dolor ni la muerte - los puede separar de su amor ni quitarles la alegría (cf. Rm 8,38-39).

«Por eso el testimonio de los mártires atrae, es aceptado, escuchado y seguido hasta en nuestros días. Ésta es la razón por la cual nos fiamos

28 Cf. Benedicto XVI, «Catequesis sobre Juan Duns Scoto en la audiencia general del $7 / 7 / 2010$ » en Los Maestros III. Franciscanos y dominicos. Catequesis de los miércoles (Buenos Aires: Agape, 2010), 99-107. 
de su palabra: se percibe en ellos la evidencia de un amor que no tiene necesidad de largas argumentaciones para convencer, puesto que habla a cada uno de lo que él ya percibe en su interior como verdadero y buscado desde tanto tiempo. En definitiva, el mártir suscita en nosotros una gran confianza, porque dice lo que nosotros ya sentimos y hace evidente lo que también quisiéramos tener la fuerza de expresar» (FR 32).

En 2019 medité largamente sobre el desafío de pensar juntamente en teología y en filosofía. ${ }^{29}$ Entonces comenté la propuesta de san Juan Pablo II: «A la parresía de la fe debe corresponder la audacia de la razón (FR 48)». Esta frase evoca la parresía paulina para anunciar el Evangelio y la consigna kantiana para atreverse a saber: ¡sapere aude! (atrévete a saber). ${ }^{30}$ Hay que entregarse a creer y pensar lo que creemos. Un pensador arriesgado es aquel que, con la sabiduría de la humildad, abre el camino a una legítima ilustración racional en el horizonte de la gratuita iluminación teologal y contribuye a renovar la forma de pensar lo que creemos y de creer lo que pensamos. ¿Quién es teólogo o teóloga? Quien cree arriesgándose a pensar y quien piensa arriesgándose a creer. La teología surge de la fe que busca y sabe entender, y de la inteligencia que busca y sabe creer, sin agrandarse en las certezas ni achicarse en las dudas, sin deslumbrarse con las luces ni apagarse con las sombras.

Esta Facultad de Teología necesita profesores y alumnos más arriesgados en la fe y más humildes en el pensamiento teológico, filosófico, pedagógico. Tiene y quiere discípulos de Jesús que, movidos por el deseo de saber como niños, comuniquen con sencillez el exceso de amor que nos desborda. Cada uno/a debe hacer teología rezando el salmo de la infancia espiritual que no se identifica con la ingenuidad de una inteligencia infantil, sino con el asombro de una sabiduría humilde (Sal 131).

29 Cf. Carlos M. Galli, «Pensar conjuntamente en teología y en filosofía. Un estilo dialogal, itinerante, integrador», Teología 129 (2019): 9-65.

30 Emmanuel Kant, «¿Qué es la llustración?» en Filosofía de la historia (Madrid: FCC, 1992), 25. 
Señor, mi corazón no se ha ensoberbecido, ni mis ojos se han vuelto altaneros. No he pretendido grandes cosas, ni he tenido aspiraciones desmedidas. No, yo aplaco y modero mis deseos: como un niño tranquilo en brazos de su madre, así está mi alma dentro de mí. Espere Israel en el Señor, desde ahora y para siempre.

Hay que correr otro riesgo y evitar otra tentación. Las evaluaciones y los rankings que marcan la educación superior pueden hacer que profesores y profesoras pierdan la moderación si se dejan seducir por una feroz competencia académica. Lo he visto aquí y en las más de cuarenta universidades en las que hablé en América y en Europa. El salmista advierte sobre las ambiciones desmedidas que superan nuestra capacidad. En cambio, un corazón filial espera la sabiduría que viene de Dios, modera los deseos excesivos, sabe retirarse a tiempo y es feliz con lo que es, sabe, hace y puede, también en la teología. Sólo en esa senda podremos ser expertos y testigos, no sólo especialistas y maestros.

En Cristo, Dios, el Máximo, se hizo Mínimo. La humildad de la fe que piensa se dice con el modesto lenguaje de la paradoja. Jesús, Dios-Hombre, es la paradoja superlativa, la paradoja de las paradojas. Las insondables dimensiones de su misterio muestran que el Deus semper maior se hizo el Deus semper minor. La kenosis, desde la encarnación hasta la cruz, revela que el supremum supremi est infimum infimi. El Maius del Dios se revela en el Minus de Cristo, el pequeño, el menor, el mínimo. El amor del Dios crucificado inspira un amor que hace pequeño lo grande y grande lo pequeño.

«Desde la cruz el lenguaje del 'más' tiene que ser completado con el lenguaje del 'menos'. Dios está también en lo pequeño, en el sufrimiento, en la negatividad. Todo ello le afecta también y lo revela. Al Dios 'mayor' hay que añadir el Dios 'Menor'. Y la trascendencia de Dios se expresa, ahora, precisamente, en mantener la simultaneidad de la grandeza y de la pequeñez de Dios». ${ }^{31}$ 


\section{Aprender a meditar mirando el corazón de María}

\section{Miramos y nos dejamos mirar por la ternura de los ojos de María}

El Pueblo de Dios tiene en María una Mujer que es su Madre en la Vida, no sólo un Modelo de vida. Desde 1974 el Padre Bergoglio expone la doctrina conciliar acerca del sensus fidei fidelium. Señala que, así como el magisterio y la teología exponen el contenido de lo que creemos, por ejemplo, acerca de María como Madre de Dios, la piedad popular manifiesta de forma viva como la Iglesia cree y ama a la Virgen. ${ }^{32}$ Su primera exhortación recuerda esta verdad sobre la sabiduría de la fe propia de todos los bautizados (EG 119). El Papa aprendió el amor a la Virgen de su abuela Rosa, inmigrante italiana nacida en Turín, Italia, la mujer que más lo marcó en la vida. Ella creció en la cultura católica piamontesa y en el contexto de lo que llamo la era mariana del siglo XIX. En el "testamento" dirigido a sus nietos, Rosa escribió que, en momentos difíciles, «una mirada a María al pie de la cruz puede hacer caer una gota de bálsamo sobre las heridas más profundas y dolorosas». ${ }^{33}$ E1 Papa aprendió a mirar y amar a la Virgen de forma cálida. Hoy mira y quiere a la Virgen como la mira y quiere un cristiano sencillo. El amor al pueblo implica aprender de su fe en Cristo y de su amor a María. Muchos, como Timoteo (2 Tm 1,5), hemos recibido la fe de nuestras madres y abuelas.

Las peregrinaciones son una imagen plástica y móvil de la vida teologal del Pueblo de Dios peregrino. Cada año casi el 80\% de los católicos latinoamericanos peregrina a un santuario mariano.

«Destacamos las peregrinaciones, donde se puede reconocer al Pueblo de Dios en camino. Allí, el creyente celebra el gozo de sentirse inmerso en medio de tantos hermanos, caminando juntos hacia Dios que los espera. Cristo mismo se hace peregrino, y camina resucitado entre los pobres. La decisión

32 Cf. Jorge M. Bergoglio, Meditaciones para religiosos (Buenos Aires: Ediciones Diego de Torres, 1982), 47.

33 Lucía Capuzzi, Rosa de los dos mundos. La historia de la abuela del Papa Francisco (Madrid: Palabra, 2015), 19. 
de partir hacia el santuario ya es una confesión de fe, el caminar es un verdadero canto de esperanza, y la llegada es un encuentro de amor» (A 259).

El Documento de Aparecida destaca la importancia de ese "intercambio de miradas".

«La mirada del peregrino se deposita sobre una imagen que simboliza la ternura y la cercanía de Dios. El amor se detiene, contempla el misterio, lo disfruta en silencio. También se conmueve, derramando toda la carga de su dolor y de sus sueños. La súplica sincera, que fluye confiadamente, es la mejor expresión de un corazón que ha renunciado a la autosuficiencia, reconociendo que solo nada puede. Un breve instante condensa una viva experiencia espiritual» (A 259).

El peregrino parte movido por la fe, camina animado por la esperanza y, al llegar, contempla con amor. El encuentro en el santuario se expresa en la mirada que contempla amorosamente a la Virgen, que simboliza la ternura de Dios. El amor se detiene, contempla el misterio, lo disfruta en silencio.

Cada vez que miramos a María volvemos a creer en lo revolucionario de la termura y del cariño de Dios (EG 288). En los santuarios marianos nos encontramos con la misericordia del Padre expresada en la ternura de la Madre. Peregrinamos para mirar y dejamos mirar por la Virgen. Francisco enseña:

«Como una verdadera madre, ella camina con nosotros, lucha con nosotros, y derrama incesantemente la cercanía del amor de Dios. A través de las distintas advocaciones marianas, ligadas generalmente a los santuarios, comparte las historias de cada pueblo que ha recibido el Evangelio, y entra a formar parte de su identidad histórica. Muchos padres cristianos piden el Bautismo para sus hijos en un santuario mariano, con lo cual manifiestan la fe en la acción maternal de María que engendra nuevos hijos para Dios. Es allí, en los santuarios, donde puede percibirse cómo María reúne a su alrededor a los hijos que peregrinan con mucho esfuerzo para mirarla y dejarse mirar por ella. Allí encuentran la fuerza de Dios para sobrellevar los sufrimientos y cansancios de la vida» (EG 286).

La mariología del Papa argentino ha sido estudiada a fondo por el presbítero brasileño Alexandre Awi Mello. Él conoció a Bergoglio en Aparecida y fue secretario de la Comisión de Redac- 
ción del Documento. Su primera obra, basada en dos entrevistas al Obispo de Roma, se titula Ella es mi mamá. Encuentros del Papa Francisco con María. Luego hizo su investigación doctoral: María Iglesia: Madre del Pueblo misionero. Papa Francisco y la piedad popular mariana a partir del contexto teológico-pastoral latinoamericano. ${ }^{34}$ Por mi parte, en 2017 escribí la obra Cristo, Maria, la Chiesa e i popoli, en la que expongo la mariología papal en diálogo con autores contemporáneos. ${ }^{35}$ El subtítulo expresa que la mirada a la Virgen está en íntima conexión con el misterio de Dios en Cristo, con la Iglesia y su misión evangelizadora, con la vida de los hombres, con el amor a la Virgen en América Latina. La ternura de los gestos del Papa muestra su amor a la Madre del Señor. En su primer diálogo con el pueblo romano Francisco invitó a rezar el Ave María, la oración mariana más popular.

En 1531 sucedió el acontecimiento guadalupano. María, la gran discípula misionera, "trajo el Evangelio a nuestra América" (A 269). En Guadalupe, Dios le regaló América Latina a la Virgen y la Virgen a América Latina. Esto se percibe en la vida cotidiana y en la cultura común de muchas personas, familias y pueblos. La Iglesia latinoamericana tiene una original piedad mariana moderna de raíz ibérica y rostro mestizo, que no se gestó directamente del cristianismo antiguo ni de la cristiandad medieval. Desde 1531 el rostro moreno de la Virgen de Guadalupe lleva a su pueblo en la pupila de sus ojos. Desde 1717 el rostro negro de Nuestra Señora Aparecida acerca a la fuente de la Vida plena. Los diversos rostros y las figuras inculturadas de la única Madre de Dios en tantas imágenes y advocaciones muestran el amor de Dios manifestado en Cristo y en María a los más pobres de los pobres. Desde 1620 el pueblo del noroeste y de nuestra tierra ama y venera a la Virgen del Valle.

34 Cf. Alexandre Awi Mello, Ella es mi mamá. Encuentros del Papa Francisco con Maria (Buenos Aires: Patris, 2014); Maria - Iglesia: Madre del Pueblo misionero. El Papa Francisco y la piedad popular mariana a partir del contexto teológico-pastoral latinoamericano (Buenos Aires: Agape, 2019).

35 Cf. Carlos M. Galli, La mariología del Papa Francisco. Cristo, María, la Iglesia y los pueblos (Buenos Aires: Agape, 2018). 
En 2016, en el discurso dirigido a los Obispos en su visita pastoral a México, Francisco se refirió al intercambio de miradas que se da entre el pueblo y La Morenita. Confesó que había reflexionado mucho sobre el misterio de esa mirada y deseaba mirarla y ser alcanzado por la ternura de sus ojos.

«Sé que mirando los ojos de la Virgen alcanzo la mirada de vuestra gente que, en Ella, ha aprendido a manifestarse. Sé que ninguna otra voz puede hablar así tan profundamente del corazón mexicano como me puede hablar la Virgen; Ella custodia sus más altos deseos, sus más recónditas esperanzas; Ella recoge sus alegrías y sus lágrimas; Ella comprende sus numerosos idiomas y les responde con ternura de Madre porque son sus propios hijos... Como hizo San Juan Diego y lo hicieron las sucesivas generaciones de los hijos de la Guadalupana, también el Papa cultivaba desde hace tiempo el deseo de mirarla. Más aún, quería yo mismo ser alcanzado por su mirada materna. He reflexionado mucho sobre el misterio de esta mirada y les ruego que acojan lo que brota de mi corazón de Pastor en este momento. Ante todo, la Virgen Morenita nos enseña que la única fuerza capaz de conquistar el corazón de los hombres es la ternura de Dios. Aquello que encanta y atrae, aquello que doblega y vence, aquello que abre y desencadena no es la fuerza de los instrumentos o la dureza de la ley, sino la debilidad omnipotente del amor divino, que es la fuerza irresistible de su dulzura y la promesa irreversible de su misericordia». ${ }^{36}$

La fe conduce a mirar y ser mirado, tocar y ser tocado, abrazar y ser abrazado por el Señor y por la Virgen. En su condescendencia, manifestada en la Encarnación, Dios quiere que experimentemos su amor y le amemos de modo connatural con nuestra humanidad. La lógica de la mirada y el contacto inspira el estilo pastoral del Papa. Todos necesitamos ser mirados, escuchados y abrazados con amor. En la homilía de la Misa de la Madre de Dios del 1 de enero de 2019 el Papa invitó a dejarse amar por María promoviendo tres actitudes: dejémonos mirar, abrazar y tomar de la mano por María. ${ }^{37}$

36 Francisco, "Con coraje profético. Discurso a los Obispos de México», L'Osservatore romano, 28/2/2016, 3 .

37 Francisco, «Homilía en la Santa Misa en la Solemnidad de Santa María, Madre de Dios», Ephemerides Mariologicae 69 (2019): 445-447. 


\section{Hacer teología en la escuela de María: meditar en el corazón}

¿Cómo enseña la Madre de Dios a hacer teología? Nos ayuda de muchas maneras, como sentimos durante la formación inicial y permanente. Señalo tres círculos concéntricos: expresa el amor entrañable de Dios; modela y sostiene muestra fe; enseña a meditar los misterios desde el corazón.

«Dios es rico en misericordia» (EF 2,4). La Misericordia es el principio hermenéutico del pontificado de Francisco. ${ }^{38}$ Ante la crisis de fe, proclama la revolución de la ternura iniciada con la Encarnación. Esa frase tiene fundamentos trinitarios, cristológicos y mariológicos. En los años ochenta el Padre Bergoglio gestó esa expresión contemplando la imagen de La Piedad. Recordaba que en el siglo XV la Piedad se representaba con la figura de una Madre con muchos hijos y en el XVI se comenzó a representar con la de la Madre compasiva con el Hijo muerto sobre sus rodillas, pero con el rostro sereno por la esperanza de la resurrección. «La Piedad es una expresión cualificada de la revolución de la ternura con que Dios quiso salvar al hombre». ${ }^{39}$ Siendo arzobispo de Buenos Aires, en sus mensajes navideños Bergoglio contemplaba la imagen del Niño Jesús y decía: Dios es ternura.

La misericordia de Dios nos llega a través de la ternura maternal de María y de la Iglesia. En el corazón de la Madre se perciben «las entrañas de misericordia de nuestro Dios» (Lc 1,78). Nuestros pueblos «encuentran la ternura y el amor de Dios en el rostro de María» (A 265). Desde antiguo ella es invocada como Madre de la misericordia, un título cargado de significado. ${ }^{40}$ La Virgen ampara y cuida a sus hijos e hijas en las necesidades y angustias. Con su sen-

38 Cf. Walter Kasper, La misericordia (Santander: Sal Terrae, 2012); Testimone della misericordia (Milano: Garzanti, 2015); Carlos M. Galli, «Revolución de la ternura y reforma de la Iglesia», Medellín 170 (2018): 73-108.

39 Cf. Jorge M. Bergoglio, Reflexiones espirituales sobre la vida apostólica (1987) (Bilbao: Mensajero, 2013), 245.

40 Cf. Salvatore M. Perrella, «Mater Misericordiae», Marianum 189/190 (2016): 171-230. 
sibilidad llega a quienes necesitan el amor misericordioso de una madre. La ternura de la Theotokos infunde una nota de dulzura.

En 1974 san Pablo VI enseñó que María «ofrece el modelo perfecto del discípulo del Señor» (MC 37). Entonces se comenzó a nombrar a María, la Madre, como discípula de Jesús, su Hijo. En 1997 san Juan Pablo II dijo que María es «la primera creyente» (RMa 26) y está unida a Jesús por la fe. «María está en contacto con la verdad de su Hijo únicamente en la fe y por la fe» (RMa 17) y, por esa misma fe, «mantiene la unión con su Hijo hasta la cruz» (RMa 18). Su mirada creyente la convierte en un testigo especial de su Persona y su obra. Por eso la Iglesia, comunidad creyente, «desde el primer momento. "miró" a María a través de Jesús, como "miró" a Jesús a través de María» (RMa 26).

La fe de María es modelo y sostén de la fe de toda la Iglesia y de cada uno. En el instante de su sí María es Israel en persona, la Iglesia en persona y lo es como persona. Esa relación es identidad en la diferencia y diferencia en la identidad. La clave del misterio es otro principio paradojal: María es una persona singular, $\mathrm{y}$, al mismo tiempo, representa a la Iglesia en su totalidad histórica - escatológica. Cuanto más una persona representa a una comunidad, tanto más es una cosa y la otra, idéntica con la realidad representada y, a la vez, diferente de aquella por su individualidad. ${ }^{41}$ María, siendo plenamente ella misma, es la persona relacional que representa plenamente la fe de toda la Iglesia.

En la Anunciación María cree la Palabra de Dios y se entrega a su voluntad - credere in Deum - respondiendo: "Yo soy la servidora del Señor, que se cumpla en mí lo que has dicho» (Lc 1,38). Por la fe María engendra al Hijo en su corazón y en su seno, y Dios comienza a hacer grandes cosas en ella (Lc 1,49). Por su fe un Niño nos ha nacido, un Hijo se nos ha dado. En la Visitación, Isabel proclama la bienaventuranza de la fe: «Feliz de ti por haber creído que se cum- 
plirá lo que te fue anunciado de parte del Señor» (Lc 1,45). Desde entonces todas las generaciones la llamamos “feliz" (Lc 1,48). Ella es la madre de los creyentes, que cuida la vida y la fe de sus hijos e hijas. Ella es «perfecta discípula y pedagoga de la evangelización» (A 1), según una frase que reúne dos títulos marianos del Documento de Puebla: «perfecta discípula» (DP 296) y «pedagoga del Evangelio» (DP 290). «Detenemos la mirada en María y reconocemos en ella una imagen perfecta de la discípula misionera» (A 364).

La fe de la Madre de Dios manifiesta que ella es «pura criatura racional» - un ser humano - como afirmó santo Tomás de Aquino al explicar el tipo de culto que se debe a la Virgen (cf. ST III, 25, 5c: pure creature). A mediados del siglo XX hubo varios pioneros en reflexionar sobre la fe de María. En el ámbito bíblico Lucien Deiss caracterizó su fe con relación a Abraham, padre de los creyentes. ${ }^{42}$ En el nivel sistemático Romano Guardini publicó una pequeña obra titulada La Madre del Señor. Allí se distanció tanto del superlativo como de la subestimación y enfatizó que ella es una creatura, un ser humano común, no una diosa-madre o un ser sobrehumano. María no llegó a priori a la plenitud, sino que fue creciendo en la fe, sobre todo en la relación con su Hijo, y recorrió un itinerario creyente para comprender el diseño de Dios. La peculiaridad de la entrega mariana es la de «la fe que persevera en lo incomprensible, aguardando a que llegue la luz de Dios». ${ }^{43}$ Guardini aplicó al misterio mariano, de forma tácita, su teoría de los opuestos y unió en la Virgen la cercanía y la distancia. «En la relación con su Hijo, aún en medio de la más entrañable confianza, debió de haber una distancia, una cierta falta de comprensión, que también se manifiesta en algunos relatos evangélicos».44

La tradición cristiana enseña a leer, contemplar y meditar en la escuela de María. Muchos iconos la representan leyendo sentada en

42 Cf. Lucien Deiss, María, hija de Sión (Bilbao: Cristiandad, 1964), 27-51.

43 Romano Guardini, La Madre del Señor (Madrid: Guadarrama, 1965), 71.

44 Romano Guardini, La Madre del Señor ... 64. 
la escena de la Anunciación, con un libro de las Escrituras sobre las rodillas. Ella es lectora y lectura del Libro, que se resume en Jesús, la Palabra de Dios. ${ }^{45}$ Ella escucha, lee, cree, medita, reza pensando y piensa rezando. Lucas señala dos veces esa cualidad de su corazón orante ante el misterio de Jesús. Ante el Niño acostado en el pesebre se conjugan la alabanza de los ángeles, la visita de los pastores y la admiración de los testigos. El evangelista agrega: «Por su lado, María guardaba todas estas cosas meditándolas en su corazón» (Lc 2,19). Una frase similar se halla cuando se narra que Jesús regresa con sus padres a Nazaret después del viaje a Jerusalén. «Su Madre conservaba estas cosas en su corazón» (Lc 2,51). Los verbos allí usados surgen de

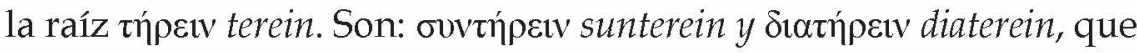
significan guardar con cuidado, registrar, recordar lo que sucede, tanto las palabras escuchadas como los hechos vistos.

María es testigo de los acontecimientos y hace memoria del paso de Dios en la historia, como canta en el Magnificat (Lc 1,46-56). Pero ella no sólo guardaba, sino que también meditaba. El verbo empleado es $\sigma v \mu \beta a ́ \lambda \lambda a v$ sumballein, que significa recoger, reunir. Simbolizar, en su sentido original, es juntar partes, unir fragmentos, relacionar aspectos, comparar interiormente, combinar asociando. Ella rumiaba las maravillas de Dios en su corazón, desde ese centro interior de la persona que une inteligencia, voluntad y sentimiento. Desde allí avanzó en la comprensión de lo que vivía desde la fe. «No se trata de un recuerdo melancólico de un pasado perdido, sino de la memoria del contenido vivo de la fe... María comprende lo que ha visto y oído. María no interpreta con su entendimiento, sino con

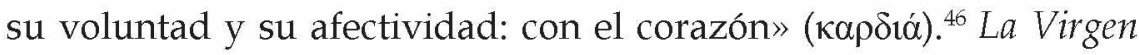
creyó y meditó. En ella se dan los dos aspectos de la fe que generan la teología: creer y entender, asentir y pensar, confiar y meditar, aceptar y comprender. Así avanzó en la peregrinación de la fe y

$45 \mathrm{Cf}$. Jean Leclercq, «María, lectura de Cristo» en Consideraciones monásticas sobre Cristo en la Edad Media (Bilbao: DDB, 1999), 43-56.

46 François Bovon, El Evangelio según san Lucas. Lc 1-9. Vol. I (Salamanca: Sígueme, 1995), $190-191$ 
desde su corazón nos enseña a hacer teología. María es el símbolo de la teología como sabiduría del corazón y corazón de la sabiduría.

2020 quedará en la historia como el año de la pandemia del COVID-19. Pero deseo recordar que también es el Año de la Palabra de Dios y el Año Mariano Nacional. Es un tiempo oportuno para meditar lo que nos enseña el Vaticano II sobre el progreso en el conocimiento de la Palabra de Dios.

\begin{abstract}
«... (la Iglesia) va creciendo en la comprensión de las cosas y de las palabras transmitidas, ya por la contemplación y el estudio de los creyentes, que las meditan en su corazón (cf. Lc 2,19.51), ya por la percepción íntima que experimentan de las cosas espirituales, ya por el anuncio de aquellos que, junto con la sucesión en el ministerio episcopal, recibieron el carisma cierto de la verdad» (DV 8).
\end{abstract}

Con este trasfondo, que evoca la tradición de la Iglesia acerca de la comprensión de la Palabra de Dios, resumo la paradoja que nos interpela para correr el riesgo de creer y caminar humildemente en el estudio de la teología. La pequeña lámpara de la fe nos hace ver con los ojos de Jesús, Luz de Luz, y nos permite mirar lejos, aprender y meditar juntos, acompañar y dejar que nos acompañen, dar un paso nuevo cada día. Nos guía María, la aurora del Evangelio, la estrella de la evangelización, la Madre que guardó la fe en su Hijo en el primer sábado santo de la historia. Por eso cantamos: ¡Cuando la noche se acerca y se oscurece la fe, Madre de todos los hombres enséñanos a decir Amén!

Amén es la primera palabra de este año académico 2020 y será la última al terminar el ciclo lectivo.

\title{
Bibliografía
}

Borghesi, Massimo, Jorge Mario Bergoglio. Una biografia intellettuale. Dialettica e mistica. Milano: Jaca Book, 2017.

Galli, Carlos María, «El "retorno" del "Pueblo de Dios"» en Virginia R. Azcuy; José C. Caamaño; Carlos M. Galli, La Eclesiología del 
Concilio Vaticano II. Buenos Aires: Agape - Facultad de Teología UCA, 2015, 405-471.

Gil, Fernando, «El tiempo es el mensajero de Dios. Esbozos para una teología de la historia del Papa Francisco», en En el Camino de Emaus: Esperanza que fecunda la historia, ed. Sociedad Argentina de Teología. Buenos Aires: Agape libros, 2017, 61-100.

Gilbert, Paul, Le ragioni della sapienza. Roma: Gregorian \& Biblical Press, 2010.

González de Cardedal, Olegario, El rostro de Cristo. Madrid: Encuentro, 2012.

Greisch, Jean, Le buisson ardent et les lumieres de la raison II. Paris: Cerf, 2002.

Guardini, Romano, La Madre del Señor. Madrid: Guadarrama, 1965.

Kasper, Walter, La misericordia. Santander: Sal Terrae, 2012.

Lafont, Ghislain, Petit essai sur le temps du pape Francois. Paris: Cerf, 2017.

Marion, Jean-Luc, «La fede e la ragione» en Credere per vedere. Torino: Lindau, 2012.

Menke, Karl Heinz, Stellvertretung. Einsedeln: Johannes, 1997.

Narvaja, José Luis, «Miguel Ángel Fiorito. Una riflessione sulla religiosità popolare nell'ambiente di Jorge Mario Bergoglio», $L a$ Civiltà Cattolica 4027 (2018): 15-93; 181-274.

Pérez del Viso, Ignacio, «El riesgo de creer en Dios», Criterio 2462 (2019): 35-38.

Pseudo Dionisio Areopagita, Teología mística I,1. Madrid: BAC, 1995.

Scannone, Juan Carlos, La teología del pueblo. Santander: Sal Terrae, 2017.

Sobrino, Jon, Jesucristo liberador. Madrid: Trotta, 1993.

Theobald, Christoph, La lezione di teología. Bologna: EDB, 2014.

Waldenfels, Hans, La svolta. Lo stile della Chiesa al tempo di papa Francesco. Bologna: EDB, 2018.

Wust, Peter, Ungewissheit und Wagnis. München: J. Küsel, 1946. 